\title{
Principles of medical ethics: implications for the disclosure of medical errors
}

This article was published in the following Dove Press journal:

Medicolegal and Bioethics

26 July 2012

Number of times this article has been viewed

\author{
Annegret F Hannawa \\ Institute of Communication and \\ Health, Faculty of Communication \\ Sciences, University of Lugano, \\ Lugano, Switzerland
}

Correspondence: Annegret F Hannawa Institute of Communication and Health, Faculty of Communication Sciences, University of Lugano,Via G Buffi I3, 6904 Lugano, Switzerland

$\mathrm{Tel}+4$ I 586664482

Fax +4I 586664647

Email annegret.hannawa@usi.ch
Abstract: This review merges interdisciplinary perspectives from communication, law, and medical ethics to advance theoretically framed standards for error disclosure. The standards reflect ethical conduct in respect to providers' decisions to disclose and their performance of error disclosures. Furthermore, the review operationalizes a list of communicative elements that implement these standards in light of communication competence theory. This work is among the first attempts to justify ethically the disclosure of error-induced adverse events and close calls, facilitating a significant contribution to medical ethics research and practice.

Keywords: medical ethics, disclosure, medical errors

\section{Introduction}

Medical errors are the eighth leading cause of death in the United States, accounting for annual patient fatalities that would equivalently result from three jumbo jets crashing every two days. ${ }^{1}$ In addition, hundreds of thousands of patients sustain preventable errorinduced injuries in their medical care each year. ${ }^{2}$ In 2001, the Joint Commission on Accreditation of Healthcare Organizations required hospitals to disclose all unanticipated care outcomes to patients and (when appropriate) their families. ${ }^{3}$ Five years later, the National Quality Forum advanced disclosure standards for health care professionals and institutions, suggesting that providers should disclose factual information, express regret, and offer an apology in response to medical errors. ${ }^{4}$ Although the justice system was slow to respond to these ethical advancements, at least 34 states have now adopted apology laws that allow health care workers to apologize to patients without having to fear that their apology will be used against them as evidence of negligence. ${ }^{5}$

Unfortunately, the apology laws promise more than what they actually deliver. Different states have different statutes, and some of them are limited. For example, Indiana protects statements of sympathy but no statements of fault, even if they are made in the context of an apology. ${ }^{6}$ The American Medical Association has attempted to alleviate this discrepancy, prescribing that "ethical obligations typically exceed legal duties". ${ }^{7}$ However, given the immense threats and emotional pressures providers commonly experience after a medical error, this contradictory framework may reinforce their instincts for self-preservation over their desire and professional obligation to tell patients the truth. ${ }^{8}$

There is an apparent need for enhanced formal control over providers' responses to medical errors, and particularly over their performance regarding error disclosure. Such efforts need to strive for clear ethical and legal vision in both disclosure intent 
and content. Providers should enforce the maintenance of personal and professional integrity by encouraging ethical conduct that is in the best interests of the patient, and at the same time adhere to the law despite its current ethical constraints. This review discusses the necessary disclosure components that would meet such an encompassing vision, and suggests a set of ethical standards that are specific to the context of error disclosure.

\section{Deciding on the best trajectory for responding to critical incidents}

Ethical conduct in the context of medical error disclosure requires two-dimensional considerations regarding a provider's decision to disclose an error and conduct of the error disclosure. Medical errors can cause harm (ie, adverse event), reach the patient without harmful impact (ie, harmless hit), or not reach the patient (ie, near miss). ${ }^{9}$ This paper adopts the standpoint that disclosure is ethically mandated in all cases. Furthermore, it is framed within communication competence theory, which posits that competent communication is both appropriate (ie, in prescribing to rules and norms) and effective (ie, in achieving goals). ${ }^{10}$ In light of this theoretical framework, competent error disclosure requires that providers have the knowledge, motivation, and skills to disclose an error appropriately and effectively.

\section{Determining the need to disclose}

Providers are often uncertain whether or not to disclose an error, particularly when it caused none or only trivial harm. ${ }^{11}$ The barriers that impede error disclosure are multiple. For example, providers commonly fear litigation and being reported to the public registry. ${ }^{11-13}$ They often perceive a lack of institutional support and do not know how to communicate to patients about an error. ${ }^{11,14}$ Personal attitudes, uncertainties about the nature of the event, perceived helplessness, and additional anxieties are further factors that commonly contribute to nondisclosure. ${ }^{15}$ Furthermore, providers often assess the likelihood of an error being discovered, the number of previous mistakes, patient characteristics, the culture of their work environment, the patient's state of consciousness, and the availability of family members. ${ }^{13}$ Given the complexity of these important considerations, it is not surprising that despite legal and ethical obligations, a majority of medical errors remain undisclosed. ${ }^{16}$

On the other side, there are also numerous arguments that promote disclosure. For example, providers often report that they perceive an ethical disclosure responsibility to their patient (ie, a desire to communicate honestly, show respect, and provide further medical care), to themselves (ie, a sense of duty and accountability, maintained integrity, and a desire to empathize and do the right thing), to their profession (ie, a desire to share lessons learned, serve as role model, strengthen trust, and change the professional culture), and to their community (ie, a desire to enhance the health of future patients, sustain trust in medicine, foster the doctor-patient relationship, and help patients understand complex causes of errors). ${ }^{15}$ In addition, an open discussion of errors with patients and colleagues can positively affect well-being. ${ }^{11}$ For example, providers have reported feeling a sense of relief and closure after disclosing an error. ${ }^{17}$ Thus, arguments support each end of the disclosure decision. However, ethical standards need to be considered to justify and clarify the proper decision.

\section{Determining the disclosure content}

Empirical evidence supports that a structured and compassionate error disclosure program can be beneficial. For example, it can reduce the number of litigations and the compensation that is paid out over time. ${ }^{18,19}$ Along the same vein, patients are less likely to seek legal advice if a physician shows himself/herself to be nonverbally involved (ie, displaying cues of immediacy, expressiveness, altercentrism, smooth interaction, composure, and positive affect) during an error disclosure. ${ }^{20}$ However, providers often do not know what to say and how to communicate with a patient after an error. ${ }^{21}$ Recent studies have attempted to illuminate this challenging task with empirical advice. Chan et al, for example, have proposed a five-point framework for effective disclosure, suggesting that patients prefer an objective explanation of the medical facts related to the error, honesty and truthfulness, empathy, a discussion about how future repetitions of the event will be prevented for all patients, and general communication skills (eg, listening, responsiveness, checking for understanding). ${ }^{22}$ Several other studies have reported that patients prefer a detailed disclosure about what happened, why it happened, the consequences, and strategies for preventing future errors. ${ }^{11,23-25}$ Leape and Burlington were the first to summarize these findings into formal guidelines on an effective response to adverse events, suggesting that disclosure should be prompt, compassionate, honest, and continuous, containing a full account of the reliable facts, a statement of responsibility and remorse, a sincere apology, and an explanation of prevention in the future. ${ }^{26}$

Although these accounts seem clear, their operationalization is complex. For example, root cause analyses take 
time and are often based on probabilities rather than facts. Therefore, an immediate disclosure may not fully account for the objective truth of the facts leading up to an event. Furthermore, the empirical findings to date do not provide any clear operationalizations of empathy that would allow providers to translate this recommended behavior into practice. Also, discussions about how future adverse events will be prevented are difficult to conduct because they depend on many institutional factors beyond the results of a time-consuming error analysis. Last but not least, no research to date has examined if and which of the above behaviors are actually beneficial for the parties involved. Preliminary studies have shown that nonverbal involvement is significantly associated with higher patient self-reports of empathy, satisfaction, trust, closeness, forgiveness, continued care, and adherence, and with lower self-reports of distress, avoidance, doctor-switching intentions, and perceived severity of the consequences of the error. ${ }^{20}$ However, these investigations have only touched the tip of an iceberg. More outcomes research is needed to investigate the causal effects of different disclosure components on objective health outcomes for patients and providers before "effective" disclosure conduct can be ethically advanced.

The apology component of the prescribed disclosure guidelines has evoked substantial controversy. Despite providers' increasing legal protection in the framework of the recently advanced apology laws, physicians still abstain from apologies because they fear that they might lead to higher malpractice premiums and be admissible in court if the patient decides to sue. ${ }^{27}$ At the same time, patients have repeatedly identified providers' failure to apologize as one of the main reasons for filing a law suit. ${ }^{28} \mathrm{~A}$ clear argument that advocates the use of apology during error disclosures is that it has healing effects for all parties involved, and a sincere apology can also help providers resolve their feelings of guilt and shame. At the same time, an apology can benefit patients by facilitating forgiveness and providing the basis for reconciliation. ${ }^{29}$ However, to date, research has not provided any causal empirical associations between an apology and concrete health-related outcomes of error disclosure.

\section{Medical error disclosure in the framework of medical ethics}

Medical errors imply a boundary violation. They occur when a provider "crossed the line" and caused physical damage to the patient. ${ }^{30}$ Thus, a competent response to medical errors is grounded in ethical conduct. Empirical findings support this argument as well. For example, the most commonly cited reason for disciplinary actions is unprofessional provider behavior rather than insufficient clinical skills. ${ }^{31}$ Similarly, patients often report "breakdown in communication" as the main reason for pursuing litigation. ${ }^{32}$ An application of the four principles of medical ethics can illuminate what constitutes ethical conduct in the context of error disclosures. Given the fiduciary nature of the doctor-patient relationship, error disclosures need to accommodate respect for autonomy, nonmaleficence, beneficence, and justice. ${ }^{33}$ The following paragraphs attempt such an application, yielding a code of ethics that is specific to the provider's decision to disclose an error, and conduct of disclosure.

\section{Principle I: respect for autonomy}

The first moral principle reflects the ethical norm of "respecting the decision-making capacities of autonomous individuals". ${ }^{33}$ This norm mirrors self-governance, privacy, freedom of will, individual choice, and self-rule free from control. Its antonym is the state of being controlled by others, or being incapable of acting on the basis of one's own intentions and goals. Autonomy rests on at least two essential conditions, ie, liberty (a person's independence from controlling influences) and agency (a person's physical and mental capacity to act). ${ }^{33}$

In order to experience liberty, a patient needs to have full access to all information related to his/her health and medical care. Thus, a provider's obligation to respect patient autonomy implies that the provider must disclose all objective information related to close calls and adverse events to the patient and/or (if the patient is incapacitated) the patient's family. Although several patient safety advocates (eg, American Medical Association code of ethics, Joint Commission on Accreditation of Healthcare Organizations) have adopted this rule, discussions around this moral obligation are controversial. For instance, Hippocrates warned that telling patients about an illness may make them anxious and worsen their condition. ${ }^{34} \mathrm{~A}$ potential solution to this problem would be to inform a third party, such as the patient's family.

However, the core practical concern does not seem to be the disclosure decision but rather the way in which the disclosure is conducted. The agency condition of patient autonomy implies that patients need to understand the content of the disclosure fully in order to make informed decisions about their health and ongoing medical care. Thus, the notion of agency suggests that disclosure is crucial, and particularly that it is important how a disclosure is communicated. For example, a provider's disclosure of an error would not be effective (and thus not ethical) if it is delivered in a language 
(eg, medical jargon) that the patient cannot understand. Furthermore, an ethical disclosure needs to compensate for the discrepancy in medical knowledge between providers and patients. In order to optimize such efforts, the provider needs to have the knowledge to "translate" the information into a language that is understood by the particular patient, the motivation to translate the medical information, and the skills to conduct the disclosure accordingly.

In the event of a medical error, patients want to be informed about their care. ${ }^{35}$ Patients are unable to understand their health situation and make competent judgments about corrective treatments and their continuing medical care unless they are informed about the events that led up to the incident, the consequences of the error on their health, and the treatments and side effects that are available to repair them. This notion defeats the therapeutic privilege argument, which solely focuses on the provider-perceived appropriateness of disclosure given the patient's condition. Instead, it takes into account the outcomes of the disclosure as a crucial criterion.

From an autonomy standpoint, a provider should not decide to withhold information related to a critical incident from a patient in an attempt to save the patient from additional harm. Nondisclosure is a defensive and passive approach to prevent further potential harm, a link that has not yet been empirically established. Rather, the provider must focus on disclosing all reliable information related to the critical event competently. Competent disclosure reflects an active effort that can promote healing. It is an approach that is both effective and appropriate and therefore reflects the most ethical way to respond to critical events. It mirrors the term "patient-centered care", ie, listening to patients and respecting their views, giving patients information in a way that they can understand, and respecting the rights of patients to be fully involved in the decision-making process. ${ }^{36}$ Patients have a right to know and must understand when errors have occurred in their care, even if they have not been harmed by them, in order to consent properly to necessary follow-up treatments and future medical care.

Unfortunately, this autonomy-based ethical rationale for disclosure goes beyond what the law currently requires providers to do. Compliance with the Joint Commission on Accreditation of Healthcare Organizations code of ethics, for example, compromises the moral right of patient autonomy because it only requires disclosure of harmful events. This concealment reinforces substandard care and implies a contractual violation of the fiduciary doctor-patient relationship. ${ }^{37}$ Patients should be able to trust their physician about anything related to their care and welfare, and they cannot make informed autonomous decisions about their subsequent care and medical treatments with incomplete or deceptive information. ${ }^{37}$ Competent error disclosure respects patient autonomy and enhances informed decision-making. Therefore, the decision to disclose and competent disclosure conduct should be ethical priorities for all providers.

\section{Principle 2: nonmaleficence}

Nonmaleficence refers to the ethical norm of avoiding causation of harm. ${ }^{33}$ It rests on the dictum of primum non nocere, ie, the provider's obligation not to injure or harm patients and to refrain from actions that would harm them. This norm captures the complexities of medical practice. The term "actions that would harm" highlights the fallibility of medicine, where harm is not always a predictable outcome but based on the probabilities of side effects and complications. Furthermore, it exposes challenging tensions between killing versus allowing to die, intending and foreseeing harmful outcomes, withholding and withdrawing life-sustaining treatments, and choosing between ordinary and extraordinary treatments. $^{33}$

Of course, adverse events imply maleficent conduct because harm was not prevented. However, subsequent nondisclosure or incompetent disclosure conduct can be maleficent as well. Providers may decide to exercise their largely discredited "therapeutic privilege" and choose not to disclose an error "for the patient's benefit". Such nondisclosure might cause serious additional harm to a patient if it impedes or delays necessary medical intervention. A patient may incur complications, for example, because $\mathrm{s} /$ he lacked information that would have allowed him or her to receive appropriate treatment on time. Withholding error-related information also commonly causes patients to lose confidence and faith in their physician's ability to help them. Furthermore, it undermines public trust in medicine and damages the therapeutic relationship between providers and patients. ${ }^{38}$ From a systems perspective, nondisclosure can also prolong recovery and undermine institutional efforts to improve patient safety, ${ }^{39}$ constituting a breach of providers' ethical duty to learn from past errors in order to protect future patients who might be harmed by a repetition of the same error.

The conduct of error disclosure can also be a harmful act if it is performed incompetently. In response to an error, patients want to hear an empathic disclosure ${ }^{22}$ and a sincere apology from their provider. A nonverbally detached disclosure, even if it is complete and truthful, can 
lead to decreased patient satisfaction, trust, forgiveness, and relational closeness to the physician. It is associated with higher patient distress, avoidance of the provider, and perceived severity of the health consequences of the mistake. Nonverbally uninvolved disclosures also lead to higher likelihood of doctor-switching, lower likelihood of continued medical care, and lower adherence with treatment recommendations. ${ }^{20}$

In sum, error disclosures that accommodate the ethical principle of nonmaleficence have to facilitate transparent reporting to the institution, as well as verbally and nonverbally effective and appropriate communication with the patient and/or the patient's family in order to prevent and intervene with the causation of additional avoidable harm (which would constitute an additional error in the chain of mistakes). Thus, the ethical dictum "do not injure" implies "do not abstain from disclosure", and "refraining from harmful actions" mandates providers to disclose errors in a competent (ie, effective and appropriate) manner.

\section{Principle 3: beneficence}

The third principle of medical ethics states that "one ought to help others". ${ }^{33}$ This norm entails actions such as preventing evil or harm, removing evil or harm, and doing or promoting good. ${ }^{33}$ Thus, beneficent acts require providers to balance benefits against risks and costs. In addition, they entail active contributions to patient welfare rather than merely refraining from doing harm. Keywords that illustrate this principle include mercy, kindness, charity, altruism, love, and humanity. Thus, beneficence encompasses active Samaritan-like acts that are conducted to benefit others, such as protecting and defending the rights of others, preventing harm from occurring to others, removing conditions that will cause harm to others, helping persons with disabilities, and rescuing persons in danger. ${ }^{33}$

\section{Protecting and defending rights}

Patients have the right to know what happens in their medical care, and beneficence ethically mandates providers to protect and defend this right. In the context of medical errors, the principle of beneficence clearly mandates disclosure of critical events as proper ethical conduct. Thus, the right to know is closely associated with the liberty condition of patient autonomy (ie, knowledge contributes to liberty). However, beneficence has a paternalistic connotations and therefore can also work against patient autonomy. For example, a provider may decide not to disclose an error or deceive in order to protect a patient. This peculiar tension between therapeutic privilege and the patient's right to know is alleviated with an overarching standard that respect for autonomy should triumph over beneficence. This standard defeats arguments that rely on therapeutic privilege and benevolent deception, which are commonly used to justify nondisclosure and deception as acts being in the patient's best interests. In this light, the only reason to conceal an error or deceive a patient would be to protect the professional's own interest, unethically positioning the welfare of the provider over the welfare of the patient. However, the patient's best interest in the case of a critical event is clearly facilitated by the provider's ethical adherence to truthful disclosure.

Patients also have a right for dignity. This standard has direct implications for the conduct of error disclosure. A beneficent disclosure requires an empathic perspective, or a "view from below", ${ }^{17}$ on behalf of the provider. It requires providers to demonstrate that the patient's experience has been treated seriously and that measures have been taken to prevent recurrence of the event. Providers should provide fair compensation for the injury that their error caused to the patient. They should offer access to counseling services and invite patients to contribute to the institution's quality improvement processes by sharing their experiences. Such empathic expressions can diminish patient anger and desire for revenge that often motivates litigation. ${ }^{30}$ Furthermore, they make it possible for patients to forgive the provider and create opportunities for patients to become part of quality improvement efforts that enhance patient outcomes. As Berlinger states, "as long as the physician cannot see that the patient's suffering, and not her own suffering, constitutes the 'view from below'; as long as she cannot admit that she is not the victim of this incident due to its perceived impact upon her career, income or self-image; as long as she fears what the injured patient might do to her rather than recognizing the disclosure as part of the narrative of caregiving, she will not be able to understand and embrace full disclosure as ethical norm". ${ }^{17}$

\section{Preventing harm and removing harmful conditions}

The second notion under the principle of beneficence, ie, "preventing harm from occurring to others," also implies that nondisclosure would be immoral. As mentioned above, nondisclosure can cause additional avoidable harm to patients, commonly undermines public trust in medicine, and may keep patients from seeking crucial follow-up treatments and continued medical care. Thus, "removing conditions that will cause harm" to patients implies that disclosures need to be 
conducted. Furthermore, the way in which an error is disclosed has ethical implications. Disclosing an error incompetently can increase patient anxiety about unexplained symptoms. An apology of acknowledged responsibility followed by an empathic disclosure might cause patients to continue trusting their physicians and to be less likely to change physicians, ${ }^{40}$ which is a condition necessary for intervention to prevent additional harm. A competent error disclosure can also facilitate future error prevention and thereby assist colleagues and institutions to improve patient safety. ${ }^{41}$ In sum, the second notion of beneficence also promotes disclosure and competent disclosure performance as ethical conduct.

\section{Helping patients}

The principle of beneficence obliges providers to help patients who have been harmed by an error (ie, in the case of adverse events). Such help needs to occur on multiple levels. For example, providers may offer emotional support (ie, caring and empathy), tangible support (ie, financial help, or assistance in completing tasks), affectionate support (eg, expression of positive emotions), and supportive social interaction (eg, to convey a sense of social companionship and integration). ${ }^{42}$ These forms of support have been associated with increased well-being and thus directly indicate beneficent conduct.

Because of the discrepancy in medical knowledge between providers and patients, providers also need to use their medical expertise ethically to persuade patients to accept the best medical treatment to repair error-induced harm. This attempt could be viewed as a reconceptualization of the therapeutic privilege; rather than choosing a (potentially harmful) defensive strategy to withhold information in an attempt to protect a patient, providers should actively engage in ethical persuasion to help patients make proper medical decisions. Patient adherence to such treatment recommendations largely depends on the provider's performance in a disclosure. For example, patients are more likely to adhere if a provider communicates nonverbal involvement (ie, displays of immediacy, expressiveness, altercentrism, smooth interaction management, composure, and positive affect) during a disclosure. ${ }^{20}$ Therefore, the decision to disclose and perform the disclosure competently are crucial components of helping patients after an errorinduced adverse event.

\section{Rescuing patients in danger}

In some cases, time pressures may require fast and efficient disclosures to save a patient's life. Also, nondisclosure may be ethically justified in certain situations when physicians have to act quickly to correct the consequences of an error and salvage a patient. Furthermore, there are instances when a patient may not be conscious and thus informed consent cannot be attained prior to necessary corrective action. Similarly, urgent medical situations may not allow time for a full empathic disclosure. In such scenarios, which will be most common in emergency care, disclosure conduct that would be considered unethical in other situations might be justified in order to save a patient's life that is endangered as the result of an error-induced adverse event.

\section{Principle 4: justice}

The provider-patient relationship is particularly prone to the ethical principle of justice because of its inherent inequitable distribution of "power" (eg, medical knowledge and decision-making) between patients and physicians. For example, providers have the power to prescribe medications, describe patients as noncompliant, and refer to failures as complications. ${ }^{30}$ This power can be used and abused to conceal and avoid the confrontation and disclosure of medical errors. In addition, neglecting the justice principle in this particular context compromises other ethical principles, particularly respect for patient autonomy.

Justice reflects the moral obligation of fairness, a norm that demands equal distribution of benefits, risks, and costs among all involved groups. Justice closely relates to the issue of entitlement ${ }^{33}$ and entails three dimensions, ie, fair distribution of scarce resources (distributive justice), respect for people's competing needs, rights, and obligations (rightsbased justice), and respect for morally acceptable laws, including potential conflicts with legislation (legal justice).

\section{Distributive justice}

Informational content, medical expertise, and privacy are three particularly scarce resources in the context of an error-induced critical event. Providers and patients need information to understand the events that led up to an error and to prevent it from happening again. They also rely on medical expertise to understand the health consequences and make competent decisions about continued care. Privacy is also a scarce resource for both patients and providers, who experience a boundary violation and loss of face, respectively. According to the principle of justice, these scarce resources need to be distributed fairly among patients and providers. Thus, all reliable informational content that is available should be shared, the most competent medical expertise should be applied collaboratively in presence of the patient, and the privacy of patients and providers needs 
to be reinstituted and maintained. In terms of the disclosure decision and content, these ethical standards clearly mandate full disclosure and respectful disclosure conduct with optimized translational efforts.

\section{Rights-based justice}

The contradictory needs, rights, and obligations of patients and providers after a critical event are multiple. For example, patients need information about the critical event for informed consent and possible insurance coverage issues. ${ }^{37}$ At the same time, providers often feel a need to safeguard incident-related information to protect themselves. Patients need comfort and coping support from their provider after a critical incident, while providers need assistance to cope with their medical error. Patients have the right to informed consent whereas providers have a right to use their therapeutic privilege to withhold information from the patient. Providers have an obligation to accept responsibility and tell patients the truth about an adverse event, while insurers and health care institutions may mandate restraint and regulate the disclosure content. Because of the complexity of these contradictory tensions, an overarching ethical standard is needed to guide ethical decisions in these convoluted dilemmas. Such systematic efforts are not yet visible in the existing literature.

\section{Legal justice}

Patients and providers are required to respect the law, but sometimes there is conflict between legal and ethical standards. This may be due to a lack of collaboration between the two fields, or due to the fact that the law is generally slow to respond to recent ethical advances. Currently, ethical and legal standards agree on demanding disclosure, but the ethically recommended disclosure content is not sufficiently defined, covered, or protected by the law. For example, apologizing remains a threat to providers because a patient may still, in some states, use an apology in court as evidence of negligence. ${ }^{6}$

In practice, the American Medical Association mandates that ethical standards should take precedence over contradictory laws. ${ }^{7}$ However, ethical standards are also encountering controversy. For instance, scholars have questioned whether it is ethical to mandate providers to harm themselves for the benefit of the patient. One of the arguments notes that it would be equally unethical to mandate legally, for example, organ donation. Despite the transgression that needs to be repaired, an ethically optimal error disclosure has to benefit both patients and providers. However, the current literature has not fully specified the disclosure content that would operationalize this goal.

Legal justice also requires fair and appropriate compensation. Patients should be able to seek appropriate restitution or compensation when they are harmed by an error. In some cases, they may not qualify for insurance benefits. Therefore, not removing the expenses associated with a medical error could be considered fraudulent. ${ }^{37}$ Ethically, reparations are owed when a person causes harm to another, particularly when the harm results from negligent action. Patients need to know about their entitlements in this regard, and the financial costs that accrue from an error need to be covered by the responsible party.

In recent years, medicine has shifted from individuals to systems. This increased complexity of medical care makes a determination of the responsible party complex. Because of multiple handoffs, it is virtually impossible for a single doctor to own all the events involved in an individual patient's care. ${ }^{43}$ Furthermore, transparency advocates discourage blaming a victim as a response to adverse events, because most errors are attributed with faulty systems that keep poorly designed health records, provide nonstandardized handoffs of information, pursue inadequate follow-up of abnormal results, and conduct faulty discharge processes. ${ }^{43}$ Thus, in modern medicine, a collective accountability approach may be the most ethical response to medical errors. However, error disclosures are conducted between individuals and not between a person and a "system". ${ }^{30}$ Thus, health care institutions and clinicians need to cooperate closely to optimize legal justice in response to error-induced adverse events.

\section{Operationalizing ethically and legally competent error disclosure}

The ethical standards discussed above need to guide competent error disclosure. However, an operationalization of the communicative components that constitute such ethical disclosure is needed. As mentioned above, some of the ethical standards conflict with each other (eg, patient autonomy and provider beneficence), and others are constrained by legal requirements (eg, insufficient protection of apology laws) and contextual frames (ie, contractual obligations to insurers). Also, several medical issues may limit the generalizability of ethical conduct in the context of error disclosure (eg, time restraints associated with urgent care, incapacitated patients, lengthy root cause analyses). The recommended ethical disclosure standards discussed in this paper need to be viewed in light of these limitations. 
All principles of medical ethics promote a positive disclosure decision. As indicated in the discussion above, disclosure of close calls and adverse events is indisputably the right thing to do. If a patient is incapacitated, providers should disclose to a third party, such as a family member or close friend. A remaining issue is the conduct of ethical disclosure. Physicians commonly want to disclose their errors, but they do not know what to say, how to conduct such a difficult conversation, and what the consequences of their disclosure might be. ${ }^{21}$ In an attempt to alleviate this challenge, the following paragraphs suggest some communicative elements that operationalize the ethical disclosure standards discussed in this paper (see Table 1 for a synopsis). Because some of the subjects remain open for future research, these communicative elements should be regarded as preliminary and incomplete.

\section{Communicating "respect for autonomy"}

Providers can optimize the ethically mandated respect for autonomy after a medical error in their post hoc communication with the patient. In order to be able to make informed autonomous decisions, the patient needs to be given a complete account of all objective information related to the critical event. Furthermore, the provider needs to ensure that the patient understands the content of the disclosure correctly. These ethical goals can only be accomplished through provider communication that is effective and appropriate. Such communication can be expressed in various ways. For example, a provider could communicate to the patient that s/he strongly enforces the ethical imperative that patients have the right to a truthful account of what happens in their care. In addition, the provider could assure the patient that their motivation is not to control, but to empower the patient to make informed decisions about their own future medical care.

Providers would also need to deliver a full and truthful account of all known facts related to the critical event (ie, the events that led up to the incident, the consequences of the error on their health, and the treatments and side effects that are available to repair them), avoiding any discussion of incorrect or unconfirmed subjective information. Providers would need to communicate this information in a language that can

Table I Ethical standards for disclosing a medical error: potential communicative elements

\begin{tabular}{|c|c|}
\hline Respect for autonomy & $\begin{array}{l}\text { - Tell the patient that you believe s/he has the right to a truthful account of what happens in his/her medical care. } \\
\text { - Provide a full and truthful account of all known facts related to the critical event (ie, the events that led up to the } \\
\text { incident, the consequences of the error for their health, and the treatments that are available to repair them). } \\
\text { Be careful not to discuss any incorrect or unconfirmed subjective information. } \\
\text { - Communicate all information in a language that can be understood by the patient. Verify that the patient has } \\
\text { comprehended what you have said - if possible, ask the patient to rephrase in his/her own words what you said. } \\
\text { Validate or, if necessary, correct the information. }\end{array}$ \\
\hline Nonmaleficence & $\begin{array}{l}\text { - Ensure the patient that you would like to correct what happened. } \\
\text { - Communicate with the patient in a way that shows your genuine remorse and empathy for the patient's situation. } \\
\text { For example, humble yourself to an eye-to-eye level with the patient when you enter the room, and show yourself } \\
\text { to be nonverbally engaged throughout the disclosure. Avoid interrupting the patient. Allow the patient to talk and } \\
\text { listen attentively to what the patient says. Respond imagining yourself in the situation of the patient. }\end{array}$ \\
\hline Beneficence & $\begin{array}{l}\text { - Adopt the "view from below" prior to entering the disclosure meeting, and try to keep this perspective throughout } \\
\text { the disclosure. } \\
\text { - Actively attempt to decrease the patient's anxiety. } \\
\text { - Tell the patient that you want him/her to have all information to be able to make competent decisions for his/her } \\
\text { continued medical care. } \\
\text { - In case of harm, use patient-centered persuasion to guide the patient into the best direction of follow-up treatment. } \\
\text { - Offer the patient access to counseling services, emotional support, professional companionship, and tangible } \\
\text { assistance if needed. } \\
\text { - Demonstrate that the incident is being treated seriously, and explain the measures that are being taken to prevent a } \\
\text { recurrence of the same event in the future. } \\
\text { - Invite the patient to contribute to the institution's quality improvement efforts by sharing his/her experiences. }\end{array}$ \\
\hline Justice & $\begin{array}{l}\text { - Tell the patient that your job is to cure, and that having to face a harmed patient is very difficult for you. } \\
\text { - Apologize for transgressing boundaries and express that you would like to reinstate the patient's privacy and trust } \\
\text { because you respect the patient. } \\
\text { - Offer your medical knowledge to the patient. } \\
\text { - With the support of your institution, offer financial assistance and provide fair compensation for any injuries that the } \\
\text { error may have caused to the patient. }\end{array}$ \\
\hline
\end{tabular}


be understood by patients. This requires advanced message encoding and decoding skills, suggesting that providers need to acquire the skills to translate medical information into a "language" that is understood by the patient, and to "read" the patient's reactions to their explanation, making sure that the patient comprehended the message correctly. A helpful communicative tool to accomplish this challenge could be to verify that the patient actually understood what was said. Specifically, a provider might ask the patient in a nonpatronizing way to rephrase in his or her own words what was said, and respectfully correct any misinterpretation of the message if necessary.

\section{Communicating "nonmaleficence"}

Communication with the patient after a medical error that meets the ethical standard of nonmaleficence needs to aim at preventing further harm. As discussed above, incompetent (ineffective and/or inappropriate) error disclosures can be maleficent. For example, verbally competent disclosures may lead to nonadherence and doctor-switching if a provider communicated in a nonverbally uninvolved way. ${ }^{20}$ Thus, to prevent additional avoidable harm, providers need to communicate with their patients in a way that shows genuine remorse and empathy. This goal requires perspective-taking skills on behalf of the provider. Specifically, providers would need to communicate with their patient from a standpoint that illustrates their complete understanding of the patient's situation, including the ways in which the critical event impacts the patient's occupational and personal quality of life. Messages that accomplish this goal include demonstrating a genuine motivation to correct the consequences of the error. Furthermore, the provider may show that the incident is being taken seriously, and explain the measures that are being taken to prevent a recurrence of the same event in the future.

\section{Communicating "beneficence"}

Active contributions to the patient's welfare after the occurrence of a medical error can also be accomplished through effective and appropriate interpersonal communication. A truthful account of what happened, for example, can decrease patient anxiety and uncertainty about unexplained symptoms. Granting the patient access to counseling services, discussing fair compensation for injuries the error may have caused, and offering various forms of social support (eg, emotional care, tangible assistance, affectionate expressions, and companionship) are direct merciful acts that translate beneficence into practice. Empathic nonverbal displays during these interactions can reinstate the dignity of the patient.
For example, providers are advised to show themselves attentive and involved during their interactions with the patient, and allow the patient to talk without interruption. In the event of harm, a provider may ask the patient whether s/he would allow them to assist in making important choices regarding corrective follow-up care. Finally, to demonstrate their investment in preventing additional harm, providers may invite the patient to contribute to their institution's quality improvement efforts by sharing his or her experiences.

\section{Communicating "justice"}

The provider-patient relationship is generally unequal in respect to decision-making power and medical knowledge. In the context of an error disclosure, the power relationship changes. Providers are at the mercy of the patient to forgive them and not to pursue legal action, humbling themselves onto the "level" of the patient. At the same time, patients are at the mercy of the provider to find out what happened in their medical care. In an attempt to meet the ethical imperative of justice, competent error disclosure needs to include communicative elements that optimize a fair distribution of these scarce resources. Providers can contribute to accomplishing this goal by offering their medical expertise to the patient. At the same time, patients need to recognize and respect the provider's difficult situation and the fallibility of the medical profession as a whole. In the midst of finding out about an error in their medical care, patients will likely not experience this empathy for the provider on their own. Thus, competent provider communication is necessary to facilitate this ethical goal. Specifically, providers could be assertive by stating that their job is to cure, and that having to face a harmed patient is very difficult for them. They could apologize to the patient for having transgressed boundaries, and express that they would like to reinstate the patient's privacy and trust. They should also solicit support from their institution to be able to offer financial assistance and provide fair compensation for injuries that the error may have caused to the patient.

In sum, according to communication competence theory, error disclosures need to be appropriate (ie, follow cultural rules and norms) and effective (ie, achieve desired goals). ${ }^{10}$ This outcome is attained when providers are motivated to disclose an error effectively and appropriately, have the knowledge about how to disclose an error effectively and appropriately, and have the skills to conduct the disclosure effectively and appropriately. Additional factors such as complexity of the event, for example, may intervene with a successful outcome. However, in a nutshell, the communicative elements discussed above (also see Table 1) 
can be viewed as a heuristic guide for the operationalization of ethical conduct during disclosures of medical errors.

\section{Limitations and suggestions for future research}

Ethical conduct can be displeasing and difficult, particularly in the context of disclosure of medical errors. However, it can also promote a learning experience. This paper applies the principles of medical ethics to the context of error disclosure, suggesting that providers have an ethical obligation to disclose errors in their medical care competently. The discussion yields a set of communicative disclosure elements that operationalize the advanced ethical standards.

It is important to note that ethical disclosure standards come with certain limitations. First, the literature suggests that patients prefer a sincere apology. Thus, providers may face an ethical conflict if their apology is not genuine. Future research is needed to elaborate this tension. Second, a causal link between the apology element and positive error disclosure outcomes has not been empirically established. In light of the legal controversy on this disclosure element, future studies need to provide causal data on this association and also test for potential mediators, such as nonverbal involvement. Third, the operationalized communicative elements assume that the error disclosure is initiated by the provider. Most of the existing literature approaches error disclosures from this standpoint. However, future research needs to evaluate to what extent a patient-elicited disclosure may be different. Fourth, multidisciplinary approaches to error disclosure that include all protagonists in the system are needed, including all patients and professionals involved. Such a systemic approach can promote partnership in this relationally challenging context and facilitate more reliable patient safety.

In sum, this work provides ethically framed disclosure standards and an operationalized list of communicative elements that providers may use when disclosing a medical error to a patient. As mentioned, these elements need to be considered in light of several limitations. However, it is hoped that they provide a valuable starting point for future investigation.

\section{Disclosure}

The author reports no conflicts of interest in this work.

\section{References}

1. DeVille K, Elliott C. To err is human: American culture, history, and medical error. In: Rubin SB, Zoloth L, editors. Margin of Error: The Ethics of Mistakes in the Practice of Medicine. Hagerstown, MD: University Publishing Group; 2000.
2. Kohn LT, Corrigan JM, Donaldson MS. To Err is Human: Building a Safer Health Care System. Washington, DC: National Academy Press; 2000.

3. Joint Commission on Accreditation of Healthcare Organizations. Revisions to Joint Commission Standards in Support of Patient Safety and Medical Health Care Error Reduction. Oakbrook Terrace, IL: Joint Commission on Accreditation of Healthcare Organizations; 2001.

4. National Quality Forum. Safe Practices for Better Healthcare. Washington, DC: National Quality Forum; 2006.

5. Gallagher TH, Studdert LL, Levinson W. Disclosing harmful medical errors to patients. N Engl J Med. 2007;356:2713-2719.

6. Raper SE. No role for apology: remedial work and the problem of medical injury. Yale J Health Policy Law Ethics. 2011;11:267-330.

7. American Medical Association Code of Ethics. Opinion 1.02 the relation of law and ethics. Available at: http://www.ama-assn.org/ama/pub/ physician-resources/medical-ethics/code-medical-ethics/opinion 102. page? Accessed July 2, 2012.

8. Hamm G, Kraman SS. New standards, new dilemmas: reflections on managing medical mistakes. Bioethics Forum. 2001;17:19-25.

9. Leape LL, Brennan TA, Laird N, et al. The nature of adverse events in hospitalized patients: results of the Harvard Medical Practice Study II. N Engl J Med. 1991;324:377-384.

10. Spitzberg BH, Cupach WR. Interpersonal Communication Competence. Beverly Hills, CA: Sage; 1984.

11. Gallagher TH, Waterman AD, Ebers AG, Berwick DM, Brennan TA. Patients' and physicians' attitudes regarding the disclosure of medical errors. JAMA. 2003;289:1001-1007.

12. Lamb RM, Studdert DM, Bohmer RMJ, et al. Hospitals' error disclosure practices: results of a national survey. Health Aff (Millwood). 2003;22: 73-83.

13. Crigger NJ, Meek VK. Toward a theory of self-reconciliation following mistakes in nursing practice. J Nurs Scholarsh. 2007;39:177-183.

14. Waring JJ. Beyond blame: cultural barriers to medical incident reporting. Soc Sci Med. 2005;60:1927-1935.

15. Kaldjian LC, Jones EW, Rosenthal GE, Tripp-Reimer T, Hillis SL. An empirically derived taxonomy of factors affecting physicians' willingness to disclose medical errors. J Gen Intern Med. 2006;21: 942-948.

16. Barach $\mathrm{P}$, Small SD. Reporting and preventing medical mishaps: lessons from nonmedical near miss reporting systems. Br Med J. 2000;320: 759-763.

17. Berlinger N. Avoiding cheap grace medical harm, patient safety, and the culture(s) of forgiveness. Hastings Cent Rep. 2003;33:28-36.

18. Kraman SS, Hamm G. Risk management: extreme honesty may be the best policy. Ann Intern Med. 1999;131:963-967.

19. COPIC. COPIC's 3Rs program, 2003. Available at: http://www. callcopic.com./copic-services/safety-and-risk/pages/3rs.asp; accessed July 16,2012

20. Hannawa AF. "Explicitly implicit": examining the importance of physician nonverbal involvement during error disclosures. Swiss Med Wkly. 2012;142:W13576.

21. Levinson W. Disclosing medical errors to patients: a challenge for health care professionals and institutions. Patient Educ Couns. 2009;76: 296-299.

22. Chan DK, Gallagher TH, Reznick R, Levinson W. How surgeons disclose medical errors to patients: a study using standardized patients. Surgery. 2005; 138:851-858.

23. Evans SM, Berry JG, Smith BJ, Esterman AJ. Anonymity or transparency in reporting of medical error: a community-based survey in South Australia. Med J Aust. 2004;180:577-580.

24. Schwappach DLB, Koeck CM. What makes an error unacceptable? A factorial survey on the disclosure of medical errors. Int J Qual Health Care. 2004;16:317-326.

25. Mazor KM, Reed GW, Yood RA, Fischer MA, Baril J, Gurwitz JH. Disclosure of medical errors: what factors will influence how patients will respond? J Gen Intern Med. 2006;21:704-710. 
26. Leape L, editor. When Things Go Wrong: Responding to Adverse Events. Burlington, MA: Massachusetts Coalition for the Prevention of Medical Errors; 2006.

27. Hoy EW. Disclosing medical errors to patients. Ear Nose Throat J. 2006;85:410, 413.

28. Kachalia A, Shojania KG, Hofer TP, et al. Does full disclosure of medical errors affect malpractice liability? The jury is still out. Jt Comm J Qual Saf. 2003;29:503-511.

29. Lazare A. Apology in medical practice: an emerging clinical skill. JAMA. 2006;296:1401-1404.

30. Berlinger N, Wu AW. Subtracting insult from injury: addressing cultural expectations in the disclosure of medical error. J Med Ethics. 2005;31: 106-108.

31. Cohen R. Assessing professional behaviour and medical error. Med Teach. 2001;23:145-151.

32. Vincent C, Young M. Why do people sue doctors? A study of patients and relatives taking legal actions. Lancet. 1994;343:1609-1613.

33. Beauchamp TL, Childress JF. Principles of Biomedical Ethics. 5th ed. New York, NY: Oxford University Press; 2001.

34. Edelstein L. Hippocratic prognosis. In: Temkin O, Temkin CL, editors. Ancient Medicine: Selected Papers of Ludwig Edelstein. Baltimore, MD: The Johns Hopkins Press; 1967.
35. Everett JP, Walters CA, Stottlemyer DL, Knight CA, Oppenberg AA, Orr RD. To lie or not to lie: resident physician attitudes about the use of deception in clinical practice. J Med Ethics. 2011;37:333-338.

36. Akhtar N. Iatrogenic nocere: ethical dimensions of clinical practice. Prof Med J. 2011;18:341-343. Available at http://www.theprofesional. com/article/2011/Vol-18-no-3/001-Prof.1745.pdf

37. Banja J. Medical Errors and Medical Narcissism. Sudbury, MA: Jones and Bartlett; 2005.

38. Hebert PC, Levin AV, Robertson G. Bioethics for clinicians: 23. Disclosure of medical error. Can Med Assoc J. 2001;164:509-513.

39. Lee SK, Cowie SE. Medical students and remediation of error. JAMA 2001;286:1082.

40. Mazor KM, Simon SR, Gurwitz JH. Communicating with patients about medical errors. Arch Intern Med. 2004;164:1690-1697.

41. Infante C. Bridging the "system's" gap between interprofessional care and patient safety: sociological insights. J Interprof Care. 2006;20: $517-525$.

42. Sherbourne CD, Stewart AL. The MOS social support survey. Soc Sci Med. 1991;32:705-714.

43. Bell SK, Delbanco T, Anderson-Shaw L, McDonald TB, Gallagher TH. Accountability for medical error. Chest. 2011;140:519-526.
Medicolegal and Bioethics

\section{Publish your work in this journal}

Medicolegal and Bioethics is an international, peer-reviewed, open access journal exploring the application of law to medical and drug research and practice and the related ethical and moral considerations. The journal is characterized by the rapid reporting of reviews, case reports, guidelines and consensus statements, original research

\section{Dovepress}

and surveys. The manuscript management system is completely online and includes a very quick and fair peer-review system. Visit http://www.dovepress.com/testimonials.php to read real quotes from published authors. 